\title{
The Effect of Electrolyte Additives on the Performance of Iron Based Anodes for NiFe Cells
}

\author{
Jorge Omar Gil Posada ${ }^{\mathrm{z}}$ and Peter J. Hall
}

Chemical and Biological Engineering, University of Sheffield, Sir Robert Hadfield Building, Sheffield S1 3JD,

United Kingdom

\begin{abstract}
Aqueous electrolyte formulations for $\mathrm{NiFe}$ cells were prepared by using lithium hydroxide and potassium sulfide additives. The incidence of each additive on the overall performance of the NiFe cell was evaluated by cycling our in-house built bismuth sulfide based iron electrodes against commercially available nickel electrodes. In order to explore the composition space relevant to our formulations, a 12 replicates $3 \times 4$ full factorial experimental design was proposed to efficiently investigate the combined effect of both additives. Our experimental results suggest potassium sulfide enhances the performance of the battery. The role of lithium hydroxide is less clear but the evidence supports that it would increase coulombic efficiency to a lesser degree than potassium sulfide. This article demonstrates that by using a relatively simple manufacturing technique and low cost materials, it is possible to develop cost effective solutions to store large amounts of energy coming from renewables.

(C) The Author(s) 2015. Published by ECS. This is an open access article distributed under the terms of the Creative Commons Attribution 4.0 License (CC BY, http://creativecommons.org/licenses/by/4.0/), which permits unrestricted reuse of the work in any medium, provided the original work is properly cited. [DOI: 10.1149/2.0451510jes] All rights reserved.
\end{abstract}

Manuscript submitted May 12, 2015; revised manuscript received July 7, 2015. Published July 28, 2015.

There is a growing demand of energy from renewable sources, ${ }^{1-6}$ however, temporary energy profiles and the availability of sun light restrict the use of such sources. Therefore, energy storage emerges as the natural solution to the asynchronous problem between energy generation and demand. ${ }^{7,8}$ There are many forms of energy storage (compressed air, hydroelectricity, electrochemical energy storage, etc.) with the potential to store grid amounts of energy coming from renewables. However, any practical solution must be efficient, safe, environmentally friendly and cost effective.

It is well known that organic electrolyte based batteries exhibit much larger energy and power density than their conventional aqueous based counterparts. Therefore, non-aqueous batteries has become the industry standard for most mobile applications (portable computers, smart telephones, etc.). Due to the flammable nature of organic solvents, safety measurements are of overriding importance when dealing with such applications. Implementing safety measurements to protect your laptop's battery is one thing, but securing energy for a much larger application, such as an airport, is a completely different story; in this case, the implementation of safety systems would be very challenging and expensive as well. This is no longer the case with aqueous batteries, where the electrolyte itself would reduce the risk of fire. In addition, the abundance and lower cost of raw materials required to produce aqueous batteries is another important aspect to consider.

Essentially, $\mathrm{NiFe}$ cells are secondary batteries which utilize iron based anodes, nickel based cathodes and concentrated solutions of $\mathrm{KOH}$ as electrolyte systems. This technology felt out of favor with the advent of cheaper lead-acid cells; however, there is a renewed interest on these batteries arising from their environmentally friendliness, longevity, and tolerance to electrical abuse (such as overcharge, over-discharge, not being used for extended periods and short-circuit conditions) and compatibility with photo-voltaics PV's. ${ }^{9-11}$ In fact, energy experts believe aqueous $\mathrm{NiFe}$ cell technology could provide a low cost solution for large scale energy storage in applications where relatively low specific energy (in the order of $30-50 \mathrm{Wh} / \mathrm{kg}$ ) is required. ${ }^{12}$

Iron is not only relatively easy to shape into different forms, but it is also the fourth most abundant element in the Earth's crust; likewise, the liquid core of the Earth is thought to be essentially composed of iron. ${ }^{13,14} \mathrm{Nickel}$, on the other hand, is less abundant than iron, but it is believed to be the second most abundant element in the Earth's core after iron, and there are still large deposits of nickel ore that can be found in many countries such as Brazil, Russia, Philipines, Canada, Australia, Indonesia, etc. ${ }^{15,16}$ Bismuth, the heaviest stable element on

zE-mail: jogp1234@yahoo.com; j.o.gil-posada@sheffield.ac.uk the periodic table, is not really abundant as it ranks $64^{\text {th }}$ in the list; ${ }^{17,18}$ however, only small amounts of this element are required to build $\mathrm{NiFe}$ cells. So there are no good reasons to believe a shortage of any of the aforementioned elements would put their prices up any time soon.

Unfortunately there are still many obstacles preventing a large scale utilization of these cells, such as considerable evolution of hydrogen, relatively low efficiency, low energy and power densities. ${ }^{9,19}$ From these problems, the evolution of hydrogen is probably the most important, for it lowers the overall cell performance by diverting part of the energy to be stored in decomposing the electrolyte. Therefore, we have utilized our in-house built $\mathrm{Bi}_{2} \mathrm{~S}_{3} / \mathrm{Fe}$ based anodes to test different electrolyte systems, so this problem would be mitigated and the overall cell performance would be enhanced.

Basically, from the anode point of view, the main process taking place during the charging of a NiFe cell is the reduction of iron (II) to iron (0); as expected, the opposite reaction would take place during the discharging process. Eq. 1 illustrates the charging (forward reaction) and discharging (backward reaction) processes of an iron electrode under strong alkaline conditions. ${ }^{19,20}$

$$
\mathrm{Fe}(\mathrm{OH})_{2}+2 e^{-} \leftrightarrow \mathrm{Fe}+2 \mathrm{OH}^{-} \quad E^{0}=-0.87 \mathrm{~V}
$$

Unfortunately, during the charging of the iron electrode, water is decomposed on its surface. As a consequence, part of the energy that is intended to be stored in the battery ended up wasted in the production of hydrogen. The net effect is a drastic reduction in the overall coulombic efficiency of the NiFe cell, as indicated by Eq. 2 .

$$
2 \mathrm{H}_{2} \mathrm{O}+2 e^{-} \leftrightarrow \mathrm{H}_{2}+2 \mathrm{OH}^{-} \quad E^{0}=-0.83 \mathrm{~V}
$$

Many attempts have been made in order to suppress or at least to reduce the extent to which water is decomposed through Eq. 2. Undoubtedly, the development of sulfur based iron electrode formulations is one of the most promising alternatives. ${ }^{21,22}$ However, the performance of the NiFe cell can also be improved by optimizing the electrolyte composition; in fact, different electrolyte additives such as wetting agents, ${ }^{23}$ long chain thiols, ${ }^{24}$ organic acids, ${ }^{25}$ among others have been investigated.

Reaching staggering capacities of nearly $800 \mathrm{mAh} \mathrm{g}^{-1}$, high performance $\mathrm{NiFe}$ cells have been reported; ${ }^{26,27}$ however, the production of such cells requires not only ultrapure reactants but also nanostructuring techniques. These aspects would have a major incidence in the final price of a commercial battery. ${ }^{26,27}$ With this in mind, we have decided to investigate the full potential of NiFe cells a cost effective solution for off-grid energy storage. ${ }^{22,28}$

In our previous publication, ${ }^{22}$ we used a multivariate approach to develop bismuth sulfide based iron electrodes. The motivation behind the selection of bismuth sulfide was its transformation into metallic 
bismuth, as represented by Eq. 3, and its supposed capability of increasing the energy barrier for water decomposition under alkaline conditions. ${ }^{27}$

$$
B i_{2} S_{3}+6 e^{-} \leftrightarrow B i+3 S^{-} \quad \mathrm{E}^{0}=-0.818
$$

Where the forward reaction takes place during the charging process of the iron electrode; likewise, the backward reaction represents the discharging process.

Here, we use an experimental design approach to efficiently investigate the incidence of lithium hydroxide and potassium sulfide as electrolyte additives to further increase the energy barrier for water decomposition, which in turn will increase the overall performance of the NiFe cell. The electrodes we used were commercially available nickel cathodes and our in-house $\mathrm{Fe} / \mathrm{Bi}_{2} \mathrm{~S}_{3}$ anodes under strong alkaline conditions. The production details of these electrodes can be found elsewhere. ${ }^{22}$ This work is a continuation of our research on battery technology, where we achieved cost effective electrode formulations rendering $\mathrm{NiFe}$ cells with coulombic efficiencies in the order of $44 \% .{ }^{22,28}$ Herein we illustrate how to improve NiFe cells by electrolyte modification, and in fact, this manuscript reveals an increase in battery performance of almost $20 \%$ (compared with our previous formulations) is possible by tailoring the electrolyte.

\section{Experimental}

Iron electrodes were produced by coating strips of nickel foam with an iron active paste which consists of varying amounts of iron powder (note that iron powder is denoted here as the "electroactive material") with a mixture of PTFE (acting as a binder) and bismuth sulfide. The chemicals and materials used to develop iron electrode formulations were of the following specifications.

- Iron powder (purity 99.5\%, < $10 \mu \mathrm{m}$ ) from Alfa Aesar

- Bismuth sulfide (purity 99.5\%, <5 $\mu \mathrm{m}$ ) from Sigma Aldrich

- PTFE (Teflon 30-N, 59.95\% solids) from Alfa Aesar

- Nickel foam (purity $99.0 \%$, density $350 \mathrm{~g} / \mathrm{m}^{2}$ ) from Sigma Aldrich

Broadly speaking, strips of nickel foam $(10 \mathrm{~mm} \times 40 \mathrm{~mm} \times$ $1.8 \mathrm{~mm}$ ) were dip coated with an iron rich electroactive paste (consisting of varying amounts of $\mathrm{Fe}, \mathrm{Bi}_{2} \mathrm{~S}_{3}$ and PTFE); the electrodes thus produced were then vacuum dried for at least 5 hours until a constant amount of electroactive material (iron) was loaded onto the electrode; this coating process was repeated until approximately $0.2-$ $0.25 \mathrm{~g}$ of iron powder were loaded on an area of approximately $1 \mathrm{~cm}^{2}$. When the process was finished, the electrodes were vacuum dried for another day to ensure consistency. More experimental details can be found elsewhere. ${ }^{22,28}$ Iron electrodes of the following characteristics were thus produced: $4 \% \mathrm{Bi}_{2} \mathrm{~S}_{3}+9 \% \mathrm{PTFE}+87 \% \mathrm{Fe}$.

We have recently investigated the role of certain electrode additives (such as potassium sulfide, bismuth sulfide, elemental bismuth and iron sulfide) in the performance of the iron electrode. ${ }^{22,28}$ However, in order to improve the performance of the iron electrode, we must consider the effect of electrolyte additives as well. With this in mind, we decided to investigate NiFe electrolyte systems using lithium hydroxide and potassium sulfide as additives. The specifications of the chemicals and materials used to produce the electrolyte solutions were as follows:

- Potassium hydroxide (purity $\geq 85.0 \%$, pellets) from Sigma Aldrich

- Potassium sulfide (purity $\geq 99.5 \%$ ) from Sigma Aldrich

- Lithium hydroxide (purity $\geq 98.0 \%$ ) from Sigma Aldrich

In house deionized water was produced by using an Elix 10-MilliQ Plus water purification system (Millipore, Eschborn, Germany). Basically, varying amounts of potassium hydroxide, potassium sulfide and lithium hydroxide were dissolved in our in-house produced deionized water.
Table I. Range of concentrations.

\begin{tabular}{ccc} 
Additive & Low $(\mathrm{M})$ & High $(\mathrm{M})$ \\
\hline $\mathrm{LiOH}$ & 0 & 0.3 \\
$\mathrm{~K}_{2} \mathrm{~S}$ & 0 & 0.6
\end{tabular}

Table II. Experimental definition of factors and levels.

\begin{tabular}{cccc} 
& \multicolumn{3}{c}{ LiOH $(0-0.3 \mathrm{M})$} \\
\cline { 2 - 4 } $\mathrm{K}_{2} \mathrm{~S}(0-0.6 \mathrm{M})$ & $\mathrm{L} 1$ & $\mathrm{~L} 2$ & $\mathrm{~L} 3$ \\
\hline L1 & $(0.0,0.0)$ & $(0.0,0.15)$ & $(0.0,0.3)$ \\
L2 & $(0.2,0.0)$ & $(0.2,0.15)$ & $(0.2,0.3)$ \\
L3 & $(0.4,0.0)$ & $(0.4,0.15)$ & $(0.4,0.3)$ \\
L4 & $(0.6,0.0)$ & $(0.6,0.15)$ & $(0.6,0.3)$
\end{tabular}

In order to investigate electrolyte additives on cell performance, electrolyte systems based upon Table I were produced.

Basically, we are not interested in exploring the effect of potassium hydroxide on the electrolyte system, what we are trying to achieve is to rationalize the incidence of minor electrolyte components in the overall performance of the battery; therefore, we have kept the composition of potassium hydroxide at a constant value of $28.5 \%$ (approximately $5.0 \mathrm{M}$ ). Based on the constancy of $\mathrm{KOH}$ and on Table I, a $3 \times 4$ full factorial design was proposed to investigate the combined effect of potassium sulfide and lithium hydroxide as electrolyte components for $\mathrm{NiFe}$ cells. The final definition of factors and levels for this experiment is shown in Table II.

The electrolyte formulations appearing in Table II were tested on a three electrode cell. In-house produced bismuth sulfide based iron electrodes were tested in a three-electrode cell (total cell volume $0.1 \mathrm{~L})$. Commercially available nickel electrodes $(18 \mathrm{~mm} \times 70 \mathrm{~mm}$ $\times 3 \mathrm{~mm}$ ) were used as the positive terminal of the cell. All potentials were measured against a mercury/mercury oxide $(\mathrm{Hg} / \mathrm{HgO})$ reference electrode $\left(E^{0}{ }_{\mathrm{Hg} / \mathrm{HgO}}=+0.098 \mathrm{~V}\right.$ vs. NHE). Experiments of charge and discharge were performed on a 64 channel Arbin SCTS. Fig. 1 provides a sketch of the cell test configuration.

Experiments of charge and discharge were conducted under galvanostatic conditions at room temperature until the steady state was reached. Cells were cycled from 0.6 to $1.4 \mathrm{~V}$ vs. $\mathrm{MMO}$ at a $\mathrm{C} / 5$ rate as indicated in Fig. 2. Formation and stabilization of the electrodes were found to be complete by the $50^{\text {th }}$ cycle of charge and discharge. More experimental details can be found elsewhere. ${ }^{22,28}$

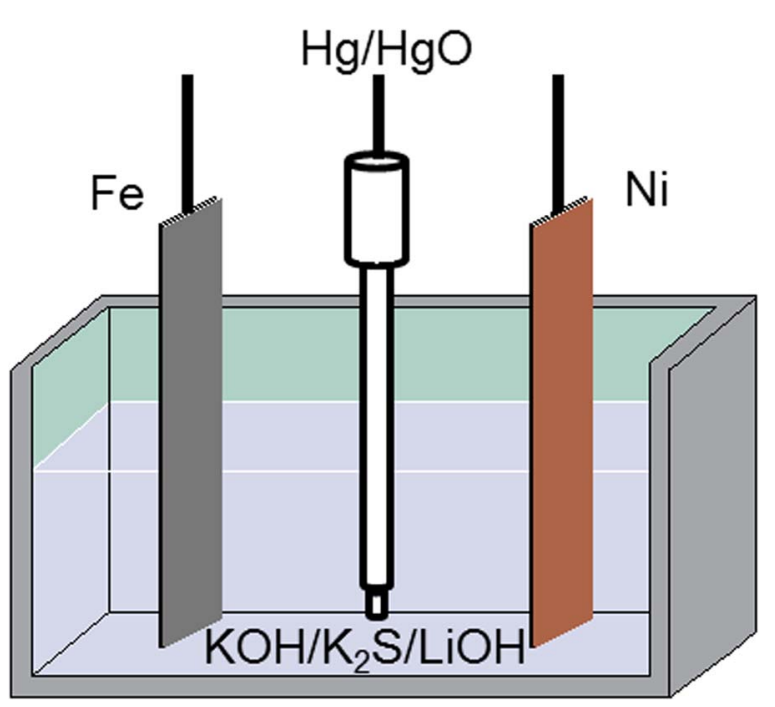

Figure 1. Test cell configuration. 


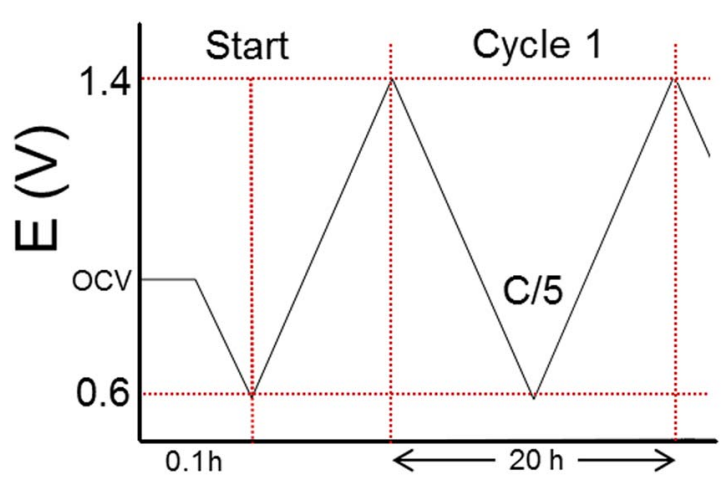

Figure 2. Charge and discharge cell testing (vs. $\mathrm{Hg} / \mathrm{HgO}$ ).

Cyclic voltammetry was conducted on an 8 channel Solartron $1470 \mathrm{E} / 1455 \mathrm{~A}$ potentiostat/galvanostat with frequency response analyzers. The electrochemical measurements were made using a conventional three-electrode glass cell. Measurements were carried out at $25^{\circ} \mathrm{C}$, by using a $\mathrm{Hg} / \mathrm{HgO}$ reference electrode, a platinum wire as a counter electrode and a concentrated solution of $\mathrm{KOH}$ as electrolyte.

\section{Results and Discussion}

It is well known that any $\mathrm{NiFe}$ cell requires a relatively long conditioning period (usually the less than the first 30 cycles of charge and discharge) before it develops its full potential as an energy storage device. Fig. 2 confirms this observation, note how the overall performance of selected batteries increases from nearly zero (in the early cycles of charge-discharge) up to more than $60 \%$.

When looking at the utilization of electroactive material, a similar behavior can be found. There is an initial period where the cells develop their potential as an energy storage device. Although, there is considerable scattering, it seems like if the conditioning period would last for less than 30 cycles. Fig. 3 illustrates how the utilization of the electroactive material evolves with the cycle number. Figs. 3 and 4 confirm the existence of the aforementioned conditioning period.

By looking at Figs. 5 and 6 we can consolidate our conclusion that after the 30th cycle, there is good reproducibility for the curves of charge and discharge. Of course, these two figures only details the performance of a NiFe cell that utilizes as electrolyte system formulation F; however, the same trend has been observed for all electrolyte

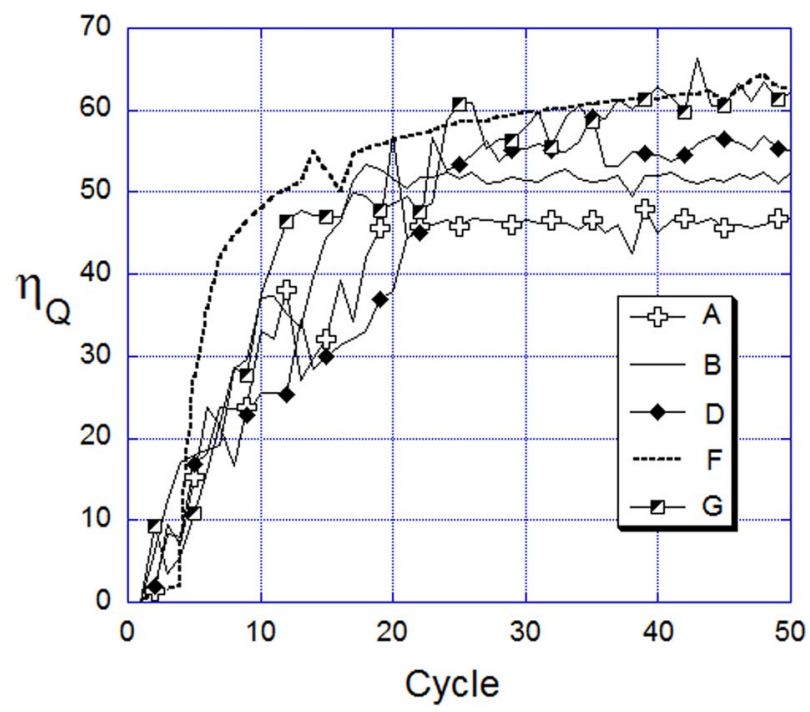

Figure 3. Coulombic efficiency versus cycle number for selected electrolyte systems. For details on compositions, please refer to Table III.

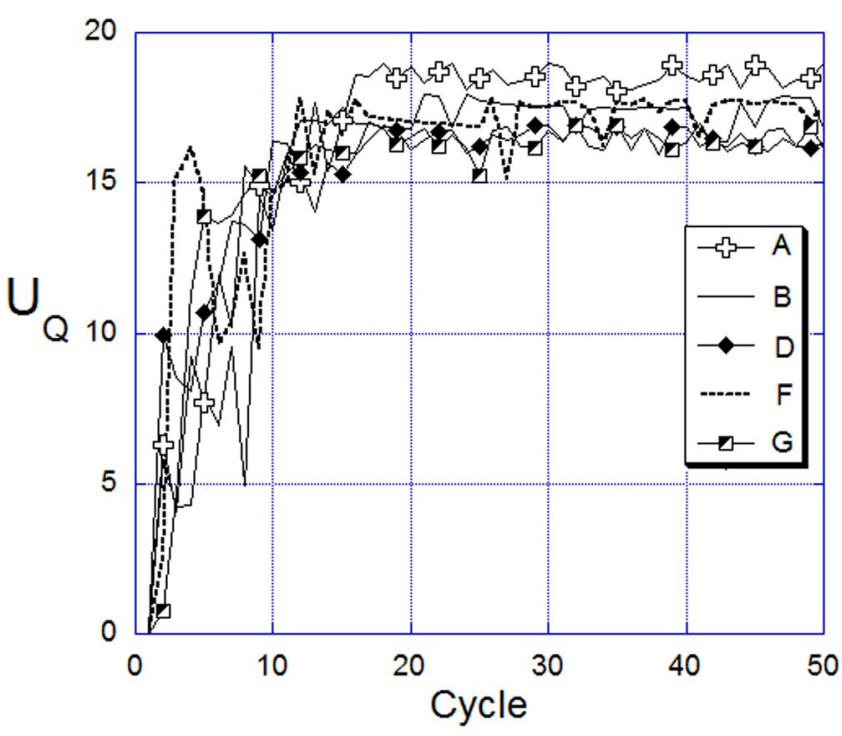

Figure 4. Utilization of the electroactive material versus cycle number for selected electrolyte systems. For details on compositions, please refer to Table III.

systems under consideration. Fig. 6 reveals a specific charge storage capacity close to $0.347 \mathrm{Ah} \mathrm{g}^{-1}$.

Although, very large capacities (close to $800 \mathrm{mAh} \mathrm{g}^{-1}$ ) have been reported for nano-structured iron electrodes, ${ }^{26,29-31}$ our cells reaching almost $350 \mathrm{mAh} \mathrm{g}^{-1}$ are worth taking seriously for we have avoided the use of any ultra-pure reactants nor we have nano-structured the electrodes (these options would have a major impact on the final price of the battery).

Table III lists experimental values of coulombic efficiency calculated for our electrodes in different electrolyte systems. As can be seen, the data exhibits large variability so a relatively large number of replicates (12 in this case) were required to increase the statistical force of the analysis. With this in mind, any sample whose coulombic efficiency or utilization of electroactive material lays more than two standard deviations from the mean was rejected.

In order to determine whether a relationship existed between the factors and responses (coulombic efficiency, utilization of

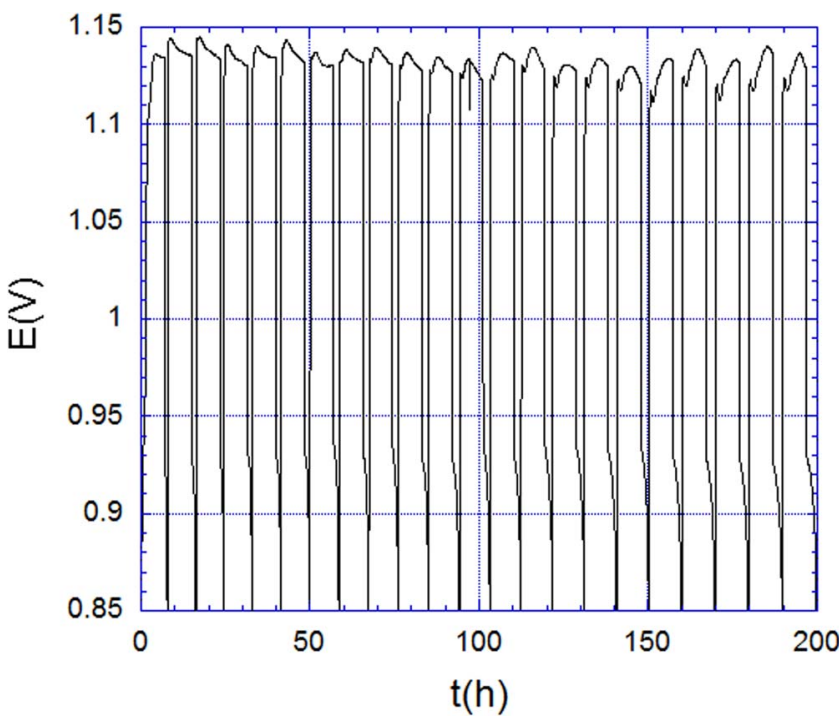

Figure 5. Charge and discharge profile for a NiFe cell using electrolyte system F (Table III) versus mercury/mercury oxide $(\mathrm{Hg} / \mathrm{HgO})$ reference electrode. 


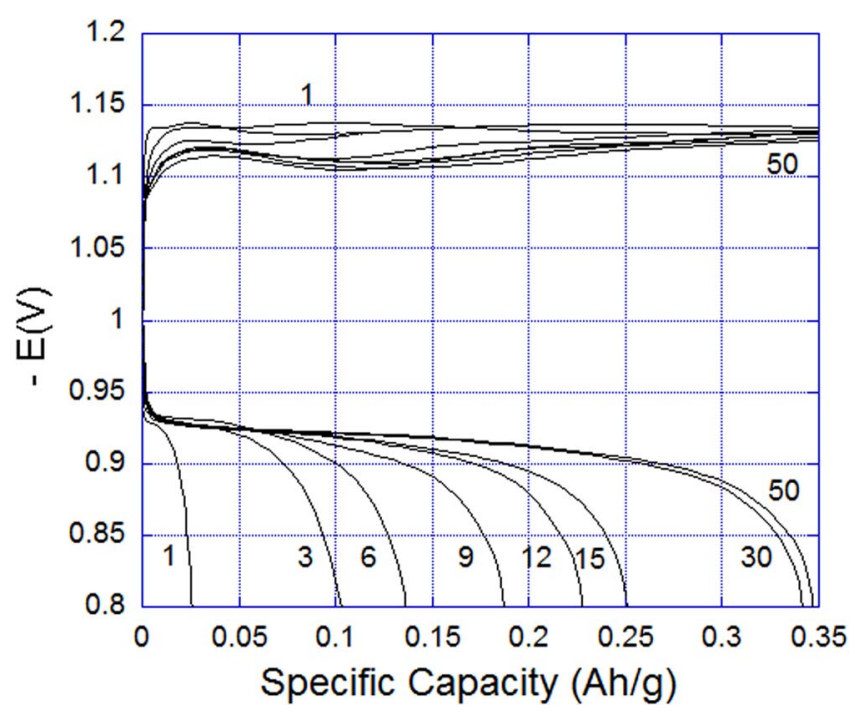

Figure 6. Selected charge and discharge curves for electrolyte system $F$ (from Table III) versus mercury/mercury oxide $(\mathrm{Hg} / \mathrm{HgO})$ reference electrode. The upper curves represent the charging of the electrode (cycles 1, 3, 6, 9, 12, 15, 30 and 50); likewise, the lower curves represent the discharging of the electrode for the corresponding cycles.

electroactive material and compositions of electrolyte additives), polynomial functions, as the one represented by Eq. 4 were used.

$$
\psi=a_{0}+a_{1} Y_{K}+a_{2} Y_{K}^{2}+a_{3} Y_{L}+a_{4} Y_{L}^{2}+a_{5} Y_{K} Y_{L}
$$

Where $\psi$ represents the response variable, either coulombic efficiency $\left(\eta_{Q}\right)$ or utilization of electroactive material $\left(U_{Q}\right)$, the a's represent the expansion coefficients (any positive sign in front of each expansion coefficient indicates a synergistic effect; likewise, any negative sign indicates an antagonistic effect.), the $\mathrm{Y}$ terms represent the composition of each component (in mol/L) and the subscripts $\mathrm{K}$ and $\mathrm{L}$ denote potassium sulfide and lithium hydroxide respectively.

Without intending to give a full introduction into regression analysis, the use of polynomial functions (such as Tutte, Scheffé, or any standard algebraic polynomial) are undoubtedly one of the most widely used empirical models for fitting functions. The reasons for this are many and include: simple form, continuity, computationally easy to implement, etc. Unfortunately, polynomial functions are well known for their poor interpolatory and extrapolatory properties. In general terms, the parameters of the model, this is the coefficients, can be found by using any form of regression analysis (in this case, we have used the least squares).

We will begin our analysis by using a standard linear model between the response variable (coulombic efficiency and the composi-

\section{Table III. Experimental design matrix.}

\begin{tabular}{ccccc} 
Cell & $\mathrm{K}_{2} \mathrm{~S}(\mathrm{M})$ & $\mathrm{LiOH}(\mathrm{M})$ & $\eta_{Q}(\exp )$ & $u_{Q}(\exp )$ \\
\hline $\mathrm{A}$ & 0.0 & 0.0 & $47.6 \pm 2.4$ & $19.4 \pm 3$ \\
$\mathrm{~B}$ & 0.0 & 0.15 & $51.3 \pm 4.0$ & $17.6 \pm 2.8$ \\
$\mathrm{C}$ & 0.0 & 0.3 & $54.3 \pm 2.8$ & $14.9 \pm 2.3$ \\
$\mathrm{D}$ & 0.2 & 0.0 & $55.8 \pm 2.9$ & $16.0 \pm 3.5$ \\
$\mathrm{E}$ & 0.2 & 0.15 & $59.9 \pm 2.0$ & $17.3 \pm 2.6$ \\
$\mathrm{~F}$ & 0.2 & 0.3 & $63.5 \pm 3.6$ & $17.7 \pm 2.5$ \\
$\mathrm{G}$ & 0.4 & 0.0 & $60.7 \pm 3.9$ & $16.9 \pm 3.2$ \\
$\mathrm{H}$ & 0.4 & 0.15 & $60.0 \pm 3.3$ & $17.0 \pm 2.5$ \\
$\mathrm{I}$ & 0.4 & 0.3 & $63.4 \pm 3.3$ & $18.3 \pm 3.1$ \\
$\mathrm{~J}$ & 0.6 & 0.0 & $55.7 \pm 2.2$ & $14.1 \pm 0.6$ \\
$\mathrm{~K}$ & 0.6 & 0.15 & $58.3 \pm 1.7$ & $15.4 \pm 3.7$ \\
$\mathrm{~L}$ & 0.6 & 0.3 & $59.9 \pm 3.0$ & $18.9 \pm 3.1$
\end{tabular}

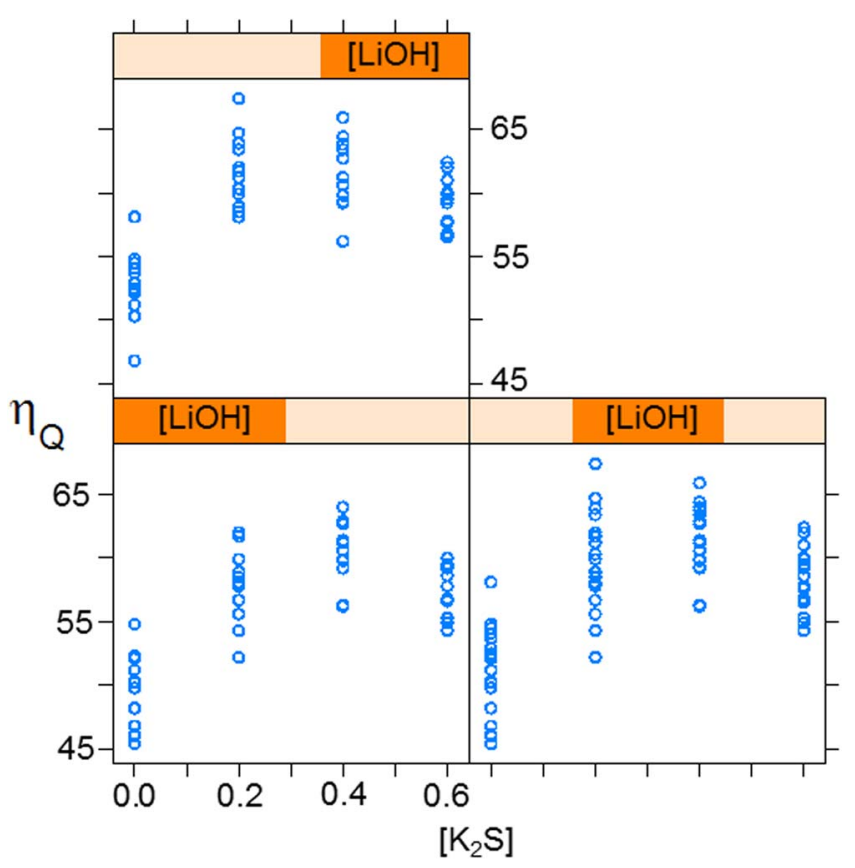

Figure 7. Incidence of potassium sulfide and lithium hydroxide on coulombic efficiency. The concentration of potassium sulfide is given in $\mathrm{mol} / \mathrm{L}$.

tions of the electrolyte additives:

$$
\eta_{Q}=51.504+11.191 \mathrm{Y}_{\mathrm{K}}+17.708 \mathrm{Y}_{\mathrm{L}}
$$

It is important to highlight that we have found no evidence that any of the least squares regression assumptions are violated, so Eq. 5 holds. The regression analysis reveals that despite a relatively low multiple correlation coefficient $(r=0.663)$, the model represented by Eq. 5 is significant ( $F$ value of 27.01), and indeed, all terms from the model are significant.

Even though the degree of linear association between variables is relatively low, due to the significance of the linear model, we could conclude that both lithium hydroxide and potassium sulfide enhance cell performance. Fig. 7 illustrates the use of a multi-scattering plot in visualizing how the response variable, coulombic efficiency, is affected by the factors, compositions of lithium hydroxide and potassium sulfide.

The bottom left part of Fig. 7 illustrates how coulombic efficiency is affected by changing the composition of potassium sulfide at low concentrations of lithium hydroxide; in this case, a second order association between variables can be suspected. Likewise, the bottom right and upper parts of Fig. 7 reveals similar information at medium and high concentrations of lithium hydroxide. By looking at the multiscattering diagram, we can see there is a quadratic rather than linear association between the variables. A parabolic tendency could also be inferred, in which higher values of coulombic efficiency are found at intermediate concentrations of potassium sulfide, irrespective of lithium hydroxide concentration.

Now it is time to use a more sophisticated model to establish the relationship between variables. We shall include an additional interaction term so Eq. 4 will become:

$$
\eta_{Q}=50.568+14.312 \mathrm{Y}_{\mathrm{K}}+23.950 \mathrm{Y}_{\mathrm{L}}-20.805 \mathrm{Y}_{\mathrm{K}} \mathrm{Y}_{\mathrm{L}}
$$

As with the previous case, the regression analysis reveals a low multiple correlation coefficient $(r=0.673)$, the model represented by Eq. 6 is still significant ( $F$ value of 18.71), and all coefficients except the interaction term are significant. Therefore, we could conclude, as with the linear model, that both lithium hydroxide and potassium sulfide enhance the cell performance.

In fact, we have used some standard transformations (logarithmic, root, and power) to try to improve the correlation; however, neither of 


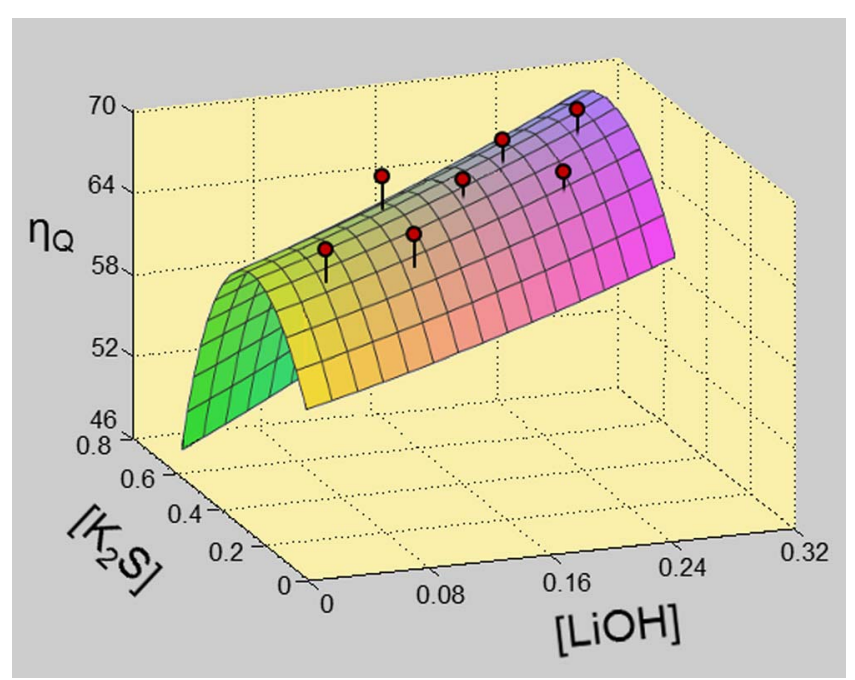

Figure 8. Second order representation of coulombic efficiency as a function of electrolyte additives.

them has achieved more than a marginal improvement in the multiple regression coefficients.

Due to the low correlation in the previous cases, a more sophisticated model is still required to investigate the problem at hand. We will now consider the full model given by Eq. 4, the following model was obtained:

$$
\eta_{\mathrm{Q}}=47.649+59.416 \mathrm{Y}_{\mathrm{K}}+20.422 \mathrm{Y}_{\mathrm{L}}-75.173 \mathrm{Y}_{\mathrm{K}}^{2}+11.759 \mathrm{Y}_{\mathrm{L}}^{2}
$$

$$
-20.805 \mathrm{Y}_{\mathrm{K}} \mathrm{Y}_{\mathrm{L}}
$$

The regression analysis reveals that the model represented by Eq. 7 is significant ( $F$ value of 58.09), the multiple correlation coefficient is relatively high $(\mathrm{r}=0.903)$; in addition, the only term that is not significant is the one related to the $\mathrm{Y}_{\mathrm{L}}{ }^{2}$. The regression analysis permits to draw the very same conclusions as with the linear model. Fig. 8 provides a three dimensional representation of Eq. 7 .

In order to find the conditions that maximize coulombic efficiency, we have use the used the fundamental theory of calculus to find stationary values of many-variable functions. $\mathrm{A} C / \mathrm{C}++$ program based on a simplex algorithm was developed to automate the process of finding the stationary values of Eq. 4 . The electrolyte conditions that maximize coulombic efficiency were determined as $\left[\mathrm{K}_{2} \mathrm{~S}\right]=0.44 \mathrm{~mol} / \mathrm{L}$ and $[\mathrm{LiOH}]=0.30 \mathrm{~mol} / \mathrm{L}$ corresponding to a coulombic efficiency of almost $69.17 \%$. However, NiFe cells using such electrolyte systems reach coulombic efficiencies in the order of $64.3 \%$ only (error in the order of $7.6 \%$ ).

Utilization of electroactive material was explained by the composition factors $\left(\mathrm{K}_{2} \mathrm{~S}\right.$ and $\mathrm{LiOH}$ content). Eq. 8 shows the second order dependency between factors on response variable.

$$
\begin{aligned}
\mathrm{U}_{\mathrm{Q}}= & 18.915-4.770 \mathrm{Y}_{\mathrm{K}}-13.5 \mathrm{Y}_{\mathrm{L}}-6.111 \mathrm{Y}_{\mathrm{K}}^{2}+8.240 \mathrm{Y}_{\mathrm{L}}{ }^{2} \\
& +45.694 \mathrm{Y}_{\mathrm{K}} \mathrm{Y}_{\mathrm{L}}
\end{aligned}
$$

Unfortunately, our experimental results show that Eq. 8 is of limited use in describing the incidence of electrolyte additives on the response variable. In general terms, the regression coefficient and the F-statistic are both very low (in the order of 0.242 and 5.36). In addition, the only term that is significant corresponds to the independent term. This would indicate that the mean (given by the independent term) could be considered representative of the entire data set. The correlation was marginally improved by using standard transformations, for which the results are not shown. Table IV compares experimental and predicted by the second order model values of coulombic efficiency and utilization of electroactive material.

As was explained, the utilization of electroactive material is poorly

\begin{tabular}{|c|c|c|c|c|c|c|}
\hline \multirow[b]{2}{*}{ Cell } & \multicolumn{2}{|c|}{ Experimental } & \multicolumn{2}{|c|}{ Second Order } & \multicolumn{2}{|c|}{$\%$ Error (min-max) } \\
\hline & $\eta_{Q}(\exp )$ & $u_{Q}(\exp )$ & $\eta_{Q}(\exp )$ & $u_{Q}(\exp )$ & $\eta_{Q}(\exp )$ & $u_{Q}(\exp )$ \\
\hline A & $47.6 \pm 2.4$ & $19.4 \pm 3$ & 47.6 & 18.9 & $4.6-5.5$ & $10.1-21.7$ \\
\hline B & $51.3 \pm 4.0$ & $17.6 \pm 2.8$ & 51.0 & 17.1 & $7.5-$ & $8.2-24.6$ \\
\hline $\mathrm{C}$ & $54.3 \pm 2.8$ & $14.9 \pm 2.3$ & 54.8 & 15.6 & $4.2-6.0$ & $5.8-24.4$ \\
\hline $\mathrm{D}$ & $55.8 \pm 2.9$ & $16.0 \pm 3.5$ & 56.8 & 17.7 & -8.1 & $9.0-31.1$ \\
\hline E & $59.9 \pm 2.0$ & $17.3=$ & 59.5 & 17.2 & 4.2 & $12.2-17.4$ \\
\hline F & $63.5 \pm 3.6$ & $17.7 \pm$ & 62.8 & 17.2 & 7.3 & $12.2-17.4$ \\
\hline G & $60.7 \pm 3.9$ & $16.9 \pm 3.2$ & 60.0 & 16.0 & 6.7 & $16.9-23.1$ \\
\hline $\mathrm{H}$ & $60.0 \pm 3.3$ & $17.0 \pm 2.5$ & 62.1 & 16.9 & $1.0-9.5$ & $13.0-16.0$ \\
\hline I & $63.4 \pm 3.3$ & $18.3 \pm 3.1$ & 64.7 & 18.2 & $1.9-8.3$ & $15.9-17.6$ \\
\hline $\mathrm{J}$ & $55.7 \pm 2.2$ & $14.1 \pm 0.6$ & 57.1 & 13.9 & $2.6-4.9$ & $2.2-6.5$ \\
\hline K & $58.3 \pm 1.7$ & $15.4 \pm 3.7$ & 58.6 & 16.1 & $2.4-3.4$ & $14.9-31.1$ \\
\hline $\mathrm{L}$ & $59.9 \pm 3.0$ & $18.9 \pm 3.1$ & 60.6 & 18.8 & $3.0-6.8$ & $13.8-18.6$ \\
\hline
\end{tabular}
represented by either the first or second order model, in situations like
Table IV. Coulombic efficiency and utilization of electroactive material for selected NiFe cells.

this extracting meaningful information from a three dimensional representation (surface response) is by no means trivial. Fig. 9 provides a better way of visualizing our data.

Fig. 9 clearly indicates that there is no such a thing as a clear trend between the composition of the electrolyte and the response factor (utilization of electroactive material). At low concentrations of $\mathrm{K}_{2} \mathrm{~S}$, the utilization of electroactive material marginally decreases with increasing the content of $\mathrm{LiOH}$. Conversely, at intermediate and high concentrations of potassium sulfide, the utilization of electroactive material slightly increases with increasing the content of $\mathrm{LiOH}$.

Although, we have used a relatively large number of replicates and the two standard deviation criteria for rejection was implemented, reproducibility remains as a major concern. As the methodology for producing electrolyte systems is straight forward, the origin of the variability can be traced to the production of the anodes. Reasons for such variability were already identified. ${ }^{22,28,32}$

We have recently shown that the use of low concentrations of potassium sulfide as an electrode additive only marginally effects the overall performance of the battery. ${ }^{22,28}$ However, the use of potassium sulfide at large concentrations seems to enhance the performance of the battery. This evidence persuades us to believe that at sufficiently large concentrations, the presence of the soluble bisulfide anion $\left(\mathrm{HS}^{-}\right)$ is sufficient to increase the coulombic efficiency of a $\mathrm{NiFe}$ cell.

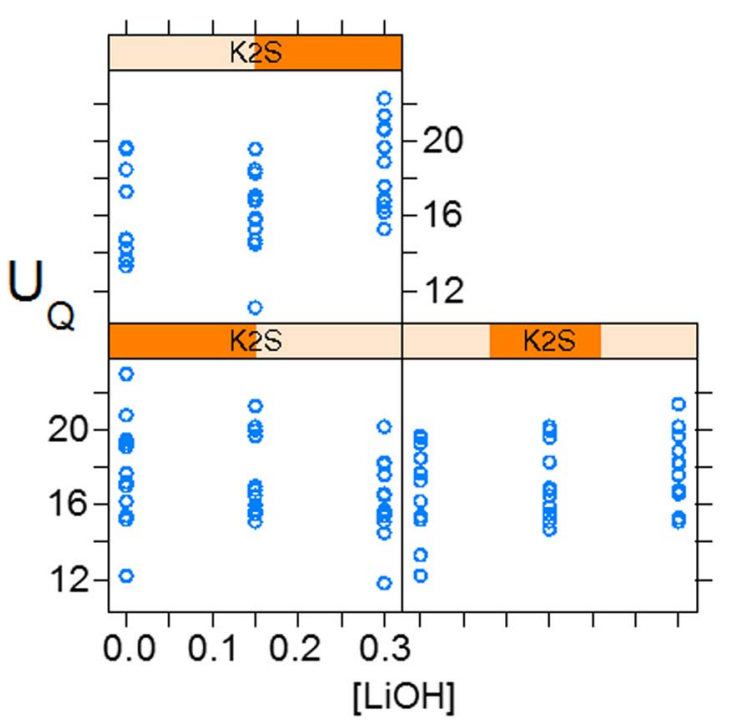

Figure 9. Incidence of potassium sulfide and lithium hydroxide on the utilization of electroactive material. The concentration of potassium sulfide is given in $\mathrm{mol} / \mathrm{L}$. 


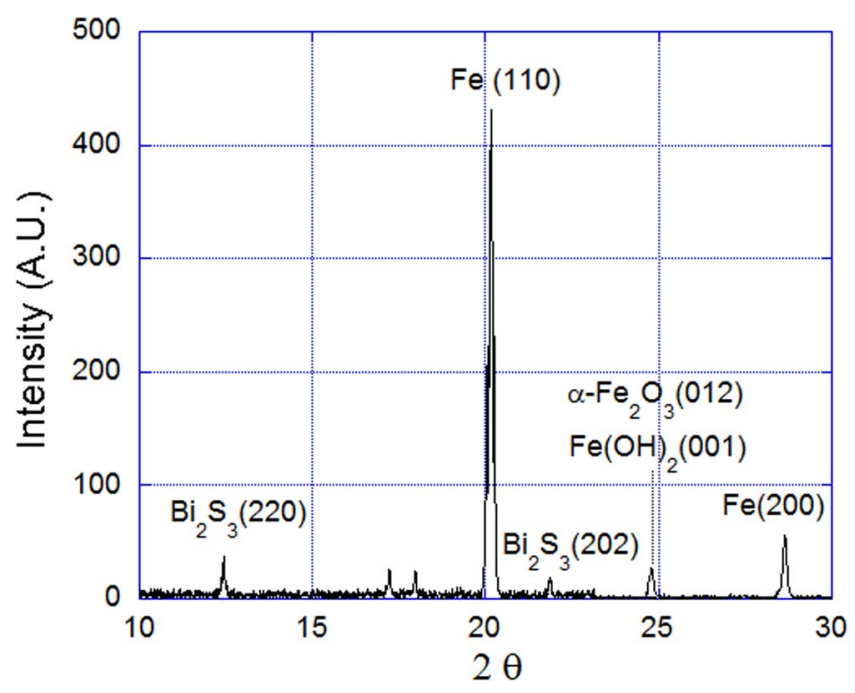

Figure 10. XRF for iron electrode after being cycled 50 times with electrolyte system F (please refer to Table III).

The role of lithium hydroxide on the performance of the $\mathrm{NiFe}$ cell is less clear. From a mere graphical perspective, it is difficult to infer that the presence of this additive actually increases coulombic efficiency; however, from the regression analysis, Eq. 7, it is clear that coulombic efficiency increases with the concentration of lithium hydroxide. However, the expansion coefficient associated with potassium sulfide is almost three times larger than the one associated with lithium hydroxide, so its incidence on battery performance is moderate-low.

As described in the experimental part, iron electrodes were produced with $4 \% \mathrm{Bi}_{2} \mathrm{~S}_{3}$, the XRD of the electrodes before and after the experiments of charge and discharge, exhibit no meaningful differences. We believe that this is because the reaction between metallic iron (the electroactive material of the electrode) and the soluble bisulphite anion is not favored. Furthermore, the utilization of the electroactive material is relatively low, so it follows there is a large amount of iron who doesn't partake on the electrochemical process and it dominates the entire XRD spectrum. Fig. 10 shows a typical XRD trace of one of our electrodes after 50 cycles of charge and discharge. This figure confirms the presence of $\alpha$-Fe but we haven't found any evidence of other polymorphs of iron (neither $\beta$-Fe nor $\gamma-\mathrm{Fe}$ ); however, we had found a very weak signal at $2 \theta=24^{\circ}$ corresponding to either $\alpha-\mathrm{Fe}_{2} \mathrm{O}_{3}$ or $\mathrm{Fe}(\mathrm{OH})_{2}$.

Although, we have found no compelling evidence of any form of iron oxyhydroxide in our samples, it has been proposed that under alkaline conditions, $\mathrm{Fe}(\mathrm{III})$ could transform into from $\beta-\mathrm{FeOOH}$ and then to $\alpha-\mathrm{Fe}_{2} \mathrm{O}_{3}$. Moreover, either goethite $(\alpha-\mathrm{FeOOH})$ or akaganeite $(\beta-\mathrm{FeOOH})$ can transform into $\alpha-\mathrm{Fe}_{2} \mathrm{O}_{3},{ }^{33,34}$ which means that the signal appearing at $2 \theta=24^{\circ}$ (Fig. 10) could very well be due to either of those species after transforming into $\alpha-\mathrm{Fe}_{2} \mathrm{O}_{3}$. However, this very same signal could be related with $\mathrm{Fe}(\mathrm{OH})_{2}$, which can be oxidized into either magnetite $\left(\mathrm{Fe}_{3} \mathrm{O}_{4}\right)$, goethite, akaganeite or lepidocrocite $(\gamma-\mathrm{FeOOH}),{ }^{35}$ which in turn could also transform into $\alpha-\mathrm{Fe}_{2} \mathrm{O}_{3}$. Magnetite can also undergo transformation into $\gamma-\mathrm{Fe}_{2} \mathrm{O}_{3}$ and then into $\alpha-\mathrm{Fe}_{2} \mathrm{O}_{3} \cdot{ }^{36}$

Although, our results confirm that battery performance is enhanced by the presence of relatively large amounts of potassium sulfide in the electrolyte, which would indicate that sulfur would play a role in the charge and discharge process of the battery, no XRD evidence of functional groups of the form $\mathrm{Fe}-\mathrm{S}$ were detected on any of the samples.

In conclusion, under our experimental conditions, we found no evidence of any reaction between potassium sulfide and either bismuth sulfide or metallic iron. However, the absence of evidence it is not

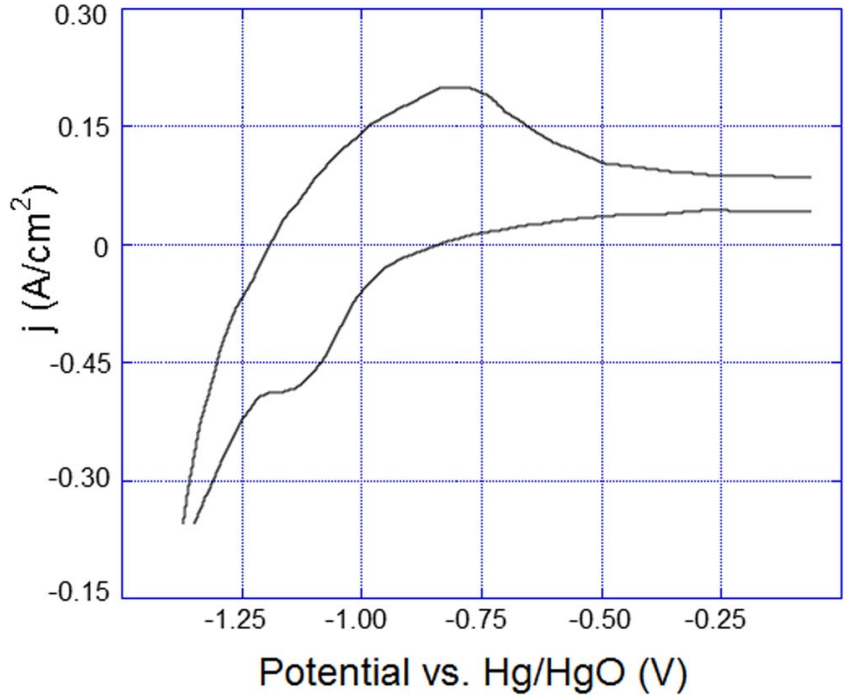

Figure 11. Triangular sweep voltammetry curves for bismuth sulfide based iron electrodes. The curves correspond to CV experiments performed in $5.1 \mathrm{M}$ $\mathrm{KOH}+0.444 \mathrm{M} \mathrm{K} 2 \mathrm{~S}+0.3 \mathrm{M} \mathrm{LiOH}$ solution at a scan rate of $0.5 \mathrm{mV} \mathrm{s}^{-1}$.

necessarily evidence of absence, therefore, we can only conclude that our results are inconclusive and more research is still needed.

In order to investigate the electrochemical properties of the cell, cyclic voltammetry experiments were conducted under conditions that maximize coulombic efficiency; this is $5.1 \mathrm{M} \mathrm{KOH}+0.44 \mathrm{M} \mathrm{K}_{2} \mathrm{~S}+$ $0.3 \mathrm{M} \mathrm{LiOH}$. Fig. 11 shows a typical cyclic voltammetry experiment of a NiFe cell using the aforementioned electrolyte system.

As shown in Fig. 11, there is a broad peak appearing from between -0.6 and $-1.0 \mathrm{~V}$ which would correspond to the oxidation of iron as represented by Eq. 9 , the production of $\delta$-FeOOH as indicated by Eq. 10, or to the production of $\mathrm{Fe}_{3} \mathrm{O}_{4}$ as illustrated by Eq. 11 .

$$
\begin{gathered}
\mathrm{Fe}+2 \mathrm{OH}^{-} \leftrightarrow \mathrm{Fe}(\mathrm{OH})_{2}+2 e^{-} \\
3 \mathrm{Fe}(\mathrm{OH})_{2}+\mathrm{OH}^{-} \leftrightarrow \delta-\mathrm{FeOOH}+\mathrm{H}_{2} \mathrm{O}+e^{-} \\
3 \mathrm{Fe}(\mathrm{OH})_{2}+2 \mathrm{OH}^{-} \leftrightarrow \mathrm{Fe}_{3} \mathrm{O}_{4}+4 \mathrm{H}_{2} \mathrm{O}+2 e^{-}
\end{gathered}
$$

Fig. 11 also reveals a change of curvature at $1.12 \mathrm{~V}$, which would correspond to the reduction of iron hydroxide into elemental iron as depicted by Eq. 9 .

It has been proposed that sulfur containing species such as bismuth sulfide and iron sulfide could improve the performance of a NiF cell by controlling the corrosion state of the iron electrode, ${ }^{37-39}$ however, the detailed mechanism is still poorly understood. ${ }^{40}$ This observation is in line with the idea that that the degree of passivation of the iron electrode is crucial to understand the evolution of hydrogen under strong alkaline conditions. Likewise, the use of potassium sulfide in the electrolyte has shown to have a positive impact in the overall performance of the battery.

It has been long recognized that the entering of hydrogen into transition metals such as iron is favored by the presence of sulfur containing compounds. ${ }^{41,42}$ In fact, species such as $\mathrm{HS}^{-}, \mathrm{S}^{2-}$ and $\mathrm{H}_{2} \mathrm{~S}$ are common promoters of hydrogen ingress into iron. ${ }^{42}$ It is our belief that the passivation of the iron electrode is determined by its hydrogen content, for hydrogen has a real incidence in the reduction of $\mathrm{Fe}$ (III) to $\mathrm{Fe}(\mathrm{II})$. The passive film on the electrode would consist many different forms of iron such as magnetite, maghemite, among others. ${ }^{43}$

The adsorption of soluble $\mathrm{HS}^{-}$can be rationalized as an electrosorptive process with charge transfer: ${ }^{44-46}$

$$
M+H S_{s \ln }^{-} \rightarrow M\left(H S^{-}\right) \rightarrow M S_{a d s}+2 e(M)+H_{s \ln }^{+}
$$

Thus any hydrogen that is produced through Eq. 12 would be neutralized by the medium and the reaction would be displaced to the 


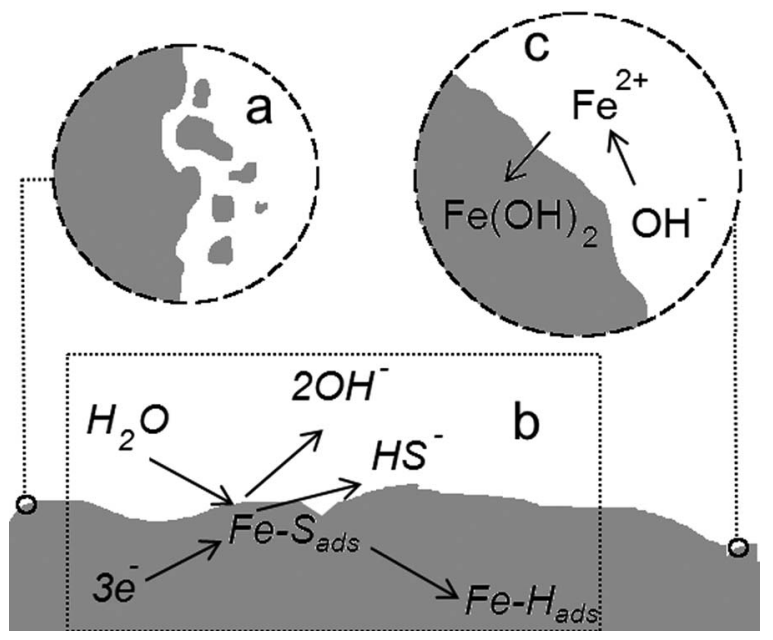

Figure 12. Important processes that determine the reactivity of the iron electrode: Generation of new surface area (a), promotion of hydrogen ingress to the electrode by the presence of sulfur species (b), and formation of iron hydroxide (c).

right (by Le Châtelier's principle). Similarly for $\mathrm{KS}^{-}$the following mechanism might occur:

$$
M+K S_{s \ln }^{-} \rightarrow M\left(K S^{-}\right) \rightarrow M S_{a d s}+2 e(M)+K_{s \ln }^{+}
$$

The newly formed $M S_{a d s}$ species will promote the ingress of hydrogen into the electrode.

$$
M S_{a d s}+2 \mathrm{H}_{2} \mathrm{O}+3 e(M) \rightarrow M H_{a d s}+\mathrm{HS}_{s \ln }^{-}+2 \mathrm{OH}^{-}
$$

It has been reported that hydrogen evolution and ingress into iron is strongly enhanced by renewal of the metal surface, ${ }^{44}$ Figs. 3 and 4 confirm that the performance of the iron electrode increases with the cycling number, until steady state conditions are reached.

Finally, the authors believe that a combined effect between the presence of sulfur species, not only in the electrolyte but also in the electrode itself, and the degradation of the electrode that occurs during the conditioning period is key to understand the reactivity of the iron electrode. These processes are depicted in Fig. 12. These ideas are supported in part by observations that have been made during the hydrogen evolution reaction under alkaline conditions. ${ }^{45}$

\section{Conclusions}

By pursuing the development of cost effective energy storage solutions, we have achieved NiFe cells that render coulombic efficiencies in the order of $64 \%$, utilization of electroactive material values close to $19 \%$ and capacities in the order of $350 \mathrm{mAh} \mathrm{g}^{-1}$. These results are very promising as we have used neither ultra-pure reactants, nor we have nano-structured our electrodes (these manufacturing alternatives would certainly impact on the final price of the battery).

It was found that under our experimental conditions and at the level of confidence $\alpha=0.05$, the addition of potassium sulfide does increase cell performance. This conclusion supports the idea that the presence of the soluble bisulfide anion $\left(\mathrm{HS}^{-}\right.$) has a real influence in improving the overall coulombic efficiency of the NiFe cell by mitigating the evolution of hydrogen on the iron electrode. Lithium hydroxide has proven to be less effective in mitigating hydrogen evolution than potassium sulfide.

Our experimental results suggest that at low concentrations of potassium sulfide, the utilization of electroactive material marginally decreases with increasing the content of lithium hydroxide. Conversely, at intermediate and high concentrations of potassium sulfide, the utilization of electroactive material slightly increases with increasing the content of lithium hydroxide. Therefore, in this case, it was not possible to find a function that properly correlates the re- sponse variable and factors. In any case, the authors believe that more investigation is still required to further clarify the role of $\mathrm{LiOH}$.

The data gathered during this project is subject to large variability; therefore, aiming to increase the statistical force of the analysis, a relatively large number of replicates (twelve in total) and the two standard deviation criteria for rejection were used.

Multi-scattering diagrams, also known as Trellis plots, provide a means to visualize the incidence of several factors on a response variable. This manuscript illustrates the usefulness of these tools in the analysis of data gathered during the characterization of relatively large numbers of half-cells.

\section{Acknowledgments}

The authors acknowledge the U.K. Engineering and Physical Sciences Research Council for supporting this work (EP/K000292/1; SPECIFIC Tranche 1: Buildings as Power Stations).

\section{References}

1. K. Hedegaard and P. Meibom, Renew. Energy, 37, 318 (2012).

2. H. Chen, T. N. Cong, W. Yang, C. Tan, Y. Li, and Y. Ding, Progress in Natural Science, 19, 291 (2009).

3. Y. Jacob, Reinforced Plastics, 45, Supplement 1, 10 (2001).

4. B. Garcia, S. L. Candelaria, D. Liu, S. Sepheri, J. A. Cruz, and G. Cao, Renew. Energy, 36, 1788 (2011).

5. J. Paska and T. Surma, Renew. Energy, 71, 286 (2014)

6. O. Akinyele and R. K. Rayudu, Sustainable Energy Technologies and Assessments, 8, 74 (2014).

7. B. Richardson and L. D. D. Harvey, Renew. Energy, 76, 432 (2015)

8. M. Delfanti, D. Falabretti, and M. Merlo, Renew. Energy, 80, 61 (2015)

9. S. Chaurey and S. Deambi, Renew. Energy, 2, 227 (1992).

10. S. Subburaj, B. N. Pushpakaran, and S. B. Bayne, Renew. Sust. Energ. Rev., 45, 219 (2015).

11. L. Ratnam, S. R. Weller, and C. M. Kellett, Renew. Energy, 75, 123 (2015).

12. P. Gao, Y. Liu, W. Lv, R. Zhang, W. Liu, X. Bu, G. Li, and L. Lei, J. Power Sources, 265, 192 (2014).

13. L. Birch, J. Geophys. Res., 69, 4377 (1964).

14. D. Morard, J. Siebert, D. Andrault, N. Guignot, G. Garbarino, F. Guyot, and D. Antonangeli, Earth Planet. Sci. Lett., 373, 169 (2013).

15. N. Oxley and N. Barcza, Minerals Engineering, 54, 2 (2013)

16. C.-L. Huang, J. Vause, H.-W. Ma, Y. Li, and C.-P. Yu, J. Clean. Prod., 84, 450 (2014).

17. K. Braunschweig, P. Cogswell, and K. Schwab, Coordin. Chem. Rev., 255, 101 (2011).

18. N. M. Leonard, L. C. Wieland, and R. S. Mohan, Tetrahedron, 58, 8373 (2002).

19. G. Halpert, J. Power Sources, 12, 177 (1984).

20. K. Shukla, S. Venugopalan, and B. Hariprakash, J. Power Sources, 100, 125 (2001).

21. K. Manohar, C. Yang, S. Malkhandi, B. Yang, G. K. S. Prakash, and S. R. Narayanan, J. Electrochem. Soc., 159, A2148 (2012).

22. J. O. Gil Posada and P. J. Hall, J. Power Sources, 262, 263 (2014).

23. K. Manohar, C. Yang, S. Malkhandi, G. K. S. Prakash, and S. R. Narayanan, J. Electrochem. Soc., 160, A2078 (2013).

24. S. Malkhandi, B. Yang, A. K. Manohar, G. K. S. Prakash, and S. R. Narayanan, J. Am. Chem. Soc., 135, 347 (2012).

25. M. J. Mackenzie, Jr. and Alvin J. Salkind, Gas Depressor Additives For Iron Electrodes, Patent number US3484291 A (1969).

26. H. Wang, Y. Liang, M. Gong, Y. Li, W. Chang, T. Mefford, J. Zhou, J. Wang, T. Regier, F. Wei, and H. Dai, Nat. Commun., 3, 1 (2012).

27. K. Manohar, S. Malkhandi, B. Yang, C. Yang, G. K. S. Prakash, and S. R. Narayanan, J. Electrochem. Soc., 159, A1209 (2012).

28. J. O. Gil Posada and P. J. Hall, J. Power Sources, 268, 810 (2014).

29. P. Periasamy, B. Ramesh Babu, and S. Venkatakrishna Iyer, J. Power Sources, 62, 9 (1996).

30. Z. Liu, S. W. Tay, and X. Li, Chem. Commun., 47, 12473 (2011).

31. M. K. Ravikumar, T. S. Balasubramanian, and A. K. Shukla, J. Power Sources, 56, 209 (1995).

32. J. O. G. Posada and P. J. Hall, Sustainable Energy Technologies and Assessments. In press

33. H. Cao, G. Wang, L. Zhang, Y. Liang, S. Zhang, and X. Zhang, ChemPhysChem, 7, 1897 (2006)

34. S. Musić, I. Czakó-Nagy, I. Salaj-Obelić, and N. Ljubešić, Mater Lett, 32, 301 (1997).

35. Hiroki Miyamoto, Teruya Shinjo, Yoshichika Bando, and T. Takada, Bulletin of the Institute for Chemical Research, Kyoto University, 45, 333 (1968).

36. B. Zhao, Y. Wang, H. Guo, J. Wang, Y. He, Z. Jiao, and M. Wu, Mater. Sci-Poland, 25, 1143 (2007).

37. V. S. Jayalakshmi, B. Nathira Begum, V. R. Chidambaram, R. Sabapathi, and V. S. Muralidharan, J. Power Sources, 39, 113 (1992)

38. E. G. Lyons and L. D. Burke, Electroanal. Chem., 170, 377 (1984)

39. T. S. Balasubramanian and A. K. Shukla, J. Power Sources, 41, 99 (1993).

40. P. Diez-Perez, F. Sanz, and P. Gorostiza, Electrochem. Commun., 8, 1595 (2006)

41. G. Williams, H. N. McMurray, and R. C. Newman, Electrochem. Commun., 27, 144 (2013). 
42. T. Flis-Kabulska, J. Flis, and T. Zakroczymski, Electrochim. Acta, 52, 7158 (2007).

43. H. B. Shao, J. M. Wang, W. C. He, J. Q. Zhang, and C. N. Cao, Electrochem. Com mun., 7, 1429 (2005).
44. C. N. Flis-Kabulska, Electrochem. Commun., 11, 54 (2009),

45. R. Solmaz and G. Kardaş, Electrochim. Acta, 54, 3726 (2009).

46. S. Y. Qian, B. E. Conway, and G. Jerkiewicz, Phys. Chem. Chem. Phys. 1, 2805 (1999). 